\title{
6-[18F]Fluoro-L-DOPA and Cerebral Blood Flow in Unilaterally MPTP-Treated Monkeys
}

\author{
Doris J. Doudet ${ }^{1}$, Richard Jed Wyatt ${ }^{2}$, Eleanor Cannon-Spoor ${ }^{2}$, Richard Suddath ${ }^{2}$, Catherine A. McLellan ${ }^{1}$ \\ and Robert M. Cohen ${ }^{1}$ \\ ${ }^{1}$ Clinical Brain Imaging Section, LCM, NIMH, IRP, \\ ${ }^{2}$ Neuropsychiatry Branch, NIMH, IRP, Bethesda, MD, USA
}

\section{SUMMARY}

Intravenous administration of ${ }^{15} \mathrm{O}$-labeled water and $6-\left[{ }^{18} \mathrm{~F}\right]-\mathrm{L}$-fluorodopa were used to assess abnormal striatal activity in monkeys after long-term recovery of unilateral lesions of the dopaminergic nigro-striatal system induced by the neurotoxin MPTP. PET data were examined in relation to behavioral and biological parameters. Cerebral blood flow and 6-[18F]-L-DOPA uptake were found to be significantly reduced in the lesioned striatum, compared to the unaffected side and to normal controls. There was no correlation between cerebral blood flow and any of the behavioral parameters. The uptake rate constant of ${ }^{18} \mathrm{~F}$ DOPA from blood to striatum and the ratios of striatum to occipital areas were highly correlated to the concentrations of homovanillic acid in the cerebrospinal fluid of the same animals but not to the rotational behavior. This MPTP-induced model of striatal dopamine deficiency in primates presents similarities with idiopathic Parkinson's disease and may be used to evaluate the effects of dopaminergic lesions and transplants on brain function.

\section{KEY WORDS}

blood flow, 18F-DOPA, positron emission tomography, MPTP, Parkinson's disease

Reprint address:

Doris J. Doudet

Section on Clinical Brain Imaging

Bldg 10/4N317, LCM, NIMH, IRP,

9000 Rockville Pike

Bethesda, MD 20892, USA

\section{INTRODUCTION}

During the past decade, the neurotoxin 1methyl-4-phenyl-1,2,3,6-tetrahydropyridine (MPTP), which is relatively selective for the dopaminergic (DA) nigro-striatal system, has attracted increasing attention. While MPTP's neurotoxic properties were discovered in humans $13,14 /$, it has been widely studied in other species. In both human and non-human primates, MPTP can produce a tangible and persistent parkinsonianlike syndrome. This syndrome mimics some of the clinical features of idiopathic Parkinson's disease (IPD), especially bradykinesia and rigidity. Pharmacologic, neuropathologic and neurochemical similarities also exist between IPD and the MPTP-induced model. The neurotoxicity of MPTP, however, has been shown to be dependant upon a number of factors, including species, age, dose and route of administration $/ 15 /$.

In the rhesus monkey, systemic injections produce a bilateral lesion of the nigro-striatal system $/ 2 /$. When MPTP is injected into one internal carotid artery, the symptoms produced are largely those of hemi-parkinsonism $/ 2 /$. This syndrome resembles the model induced by injection of 6-hydroxydopamine (6-OHDA) in the substantia nigra developed by Marshall and Ungerstedt $/ 17 /$ in the rodent. In the rodent, one can make an in vivo assessment of the extent of the DA lesion by the intensity of spontaneous turning behavior, as well as the turning behavior induced by the administration of substances that stimulate the dopamine (DA) system such as apomorphine and amphetamine.

In this study, using 6-[18F]fluoro-L-3,4dihydroxyphenylalanine (18F-DOPA) and ${ }^{15} \mathrm{O}$ labeled water with positron emission tomography 
(PET), we examined the pattern of distribution of 18F-DOPA and cerebral blood flow (CBF) in the brains of rhesus monkeys after clinical recovery from unilateral MPTP treatment and compared the results with behavioral data. We discuss the model of Parkinson's disease induced by intra-arterial injection of MPTP in light of these data.

\section{MATERIALS AND METHODS}

\section{Animal procedures}

Eight naive male rhesus monkeys, rendered hemi-parkinsonian by MPTP injections into the internal carotid artery were used in this study. The animals' ages ranged from 3 to 14 years old (Table 1). The age was obtained either from birth records, or from evaluation of the teeth and medical histories.

\section{MPTP infusions}

The method of MPTP administration was similar to that described by Bankiewicz et al. /1/ with the following modifications: Under sterile conditions, the neck area above the right carotid artery was incised and the artery isolated. All branches except the internal carotid branch were ligated. MPTP (solubilized in $0.1 \mathrm{~N} \mathrm{HCL}, 0.3$ to $0.7 \mathrm{mg} / \mathrm{kg}$ in $20-30 \mathrm{ml}$ heparizined Ringer's lactate) was then slowly infused over $20 \mathrm{~min}$ through a sterile $22 \mu \mathrm{m}$ Millipore filter and a 25 gauge indwelling butterfly needle at a rate of 1-1.5 $\mathrm{ml} / \mathrm{min}$.

Generally, the animal received an initial infusion of $0.35 \mathrm{mg} / \mathrm{kg}$ of MPTP. This was followed by an observation period of at least three weeks in which hypokinesia and contralateral limb movements were evaluated. The extent of neurological impairment and the animal's ability to consistently display apomorphine-induced rotations of at least 75 turns $/ \mathrm{h}$, determined whether another MPTP infusion was given. Up to four MPTP infusions were given, usually using a dose lower than the initial dose. No animal was infused more often than once every three weeks. The total cumulative dose varied from $0.35 \mathrm{mg} / \mathrm{kg}$ to 1.5 mg/kg (Table 1).

\section{Behavioral assessment}

The neurological impairments observed after acute MPTP treatment tended to regress with time; however, after two or more MPTP treatments, some mild contralateral impairments remained after maximum recovery (5-6 months). This did not significantly interfere with the animals' ability to eat, drink or groom. None of the unilateral MPTPtreated animals in this study required L-DOPA therapy. The animals were carefully observed in their cages during the weeks preceding and following the PET study and were rated for hypokinesia, tremor, posture, vocalization and feeding as normal, mildly, moderately or severely impaired.

Following the last MPTP injection, rotational behaviors of the animals were observed. The animals were tested once per month, occasionally twice per month, until a stable pattern of contralateral rotation developed. The animals were observed in their home cages by two investigators. Following a $5 \mathrm{~min}$ observation period, during which the number of spontaneous rotations was recorded, the animals were injected with apomorphine $(0.15 \mathrm{mg} / \mathrm{kg})$ in the gluteal muscle. Three hundred and sixty degree rotations were counted over a $60 \mathrm{~min}$ period. The investigators' totals were averaged for each session. The direction of the animals' turns were recorded as either ipsilateral (I) or contralateral (C) to the side of the lesion. Table 1 depicts the mean rotations for each animal during 3 sessions during the weeks preceding and/or following the PET scan.

In addition, as described earlier $/ 6 /$, CSF samples were removed from the cerebellomedullary cistern under aseptic conditions and immediately frozen until assayed using standard HPLC techniques $/ 28 /$ for homovanillic acid (HVA), 5-hydroxyindoleacetic acid (5HIAA) and 3-methoxy-4-hydroxyphenylglycol (MHPG). Assay results were averaged for each animal (Table 1).

\section{PET studies}

In the 8 to 14 months following the last MPTP administration, when stable rotational behavior was consistently observed, the animals received a PET 
空点岕

范茞

엉

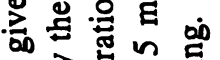

.

o d

i 8 त

(

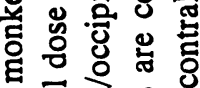

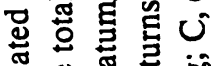

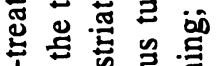

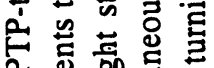

运恋要

互产要 总

骆害

里

$\infty$ 策

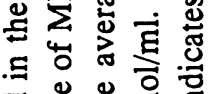

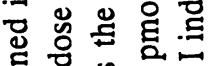

苨导总吉

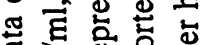

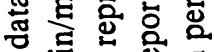

젼 $\$$

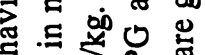

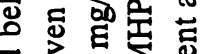

完 㟧

志起要

范焉颔总

品 명

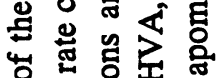

究苋出

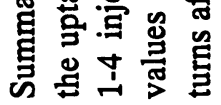

\begin{tabular}{|c|c|c|c|c|c|c|c|c|}
\hline 号密 & $\begin{array}{l}0 \\
\text { 이 } \\
\text { N }\end{array}$ & $\begin{array}{l}u \\
-1 \\
N\end{array}$ & $\begin{array}{c}u \\
n \\
0 \\
0-1\end{array}$ & $\left|\begin{array}{l}0 \\
0 \\
0 \\
0 \\
-1\end{array}\right|$ & $\begin{array}{l}u \\
m \\
m \\
-\end{array}$ & $\begin{array}{l}u \\
m \\
0 \\
0 \\
-1\end{array}$ & $\begin{array}{l}u \\
N\end{array}$ & $\begin{array}{l}0 \\
0 \\
\end{array}$ \\
\hline 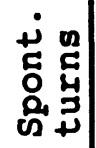 & $\begin{array}{l}-H \\
m\end{array}$ & $\begin{array}{l}- \\
- \\
m \\
-1\end{array}$ & $\begin{array}{l}-1 \\
8 \\
0\end{array}$ & $\begin{array}{c}-1 \\
0\end{array}$ & $\begin{array}{c}-1 \\
m \\
\mathcal{O}\end{array}$ & $\begin{array}{l}H \\
\sigma\end{array}$ & $\begin{array}{l}-1 \\
0\end{array}$ & $\vec{N}$ \\
\hline 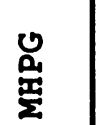 & N & 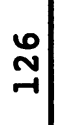 & $\begin{array}{l}\infty \\
\infty\end{array}$ & 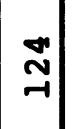 & $\begin{array}{l}n \\
-1 \\
-1\end{array}$ & ?̧ & $ㅇ$ & \\
\hline 趈 & $\begin{array}{c}\vec{n} \\
\mathrm{~m}\end{array}$ & $\underset{m}{\infty}$ & : & $\stackrel{\substack{m \\
\sim}}{N}$ & 옹 & : & $\underset{\sim}{\infty}$ & $\underline{\alpha}$ \\
\hline$\sum^{\complement}$ & 임 & ơ & 욤 & $\stackrel{0}{2}$ & 웜 & $\stackrel{n}{N}$ & ํํ & \\
\hline 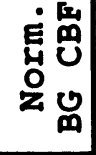 & $\begin{array}{l}n \\
0 \\
-i\end{array}$ & $\begin{array}{c}8 \\
0 \\
-1\end{array}$ & $\begin{array}{l}n \\
0 \\
-1\end{array}$ & $\begin{array}{c}-1 \\
0 \\
-1\end{array} \mid$ & $\begin{array}{l}0 \\
0 \\
0\end{array}$ & $\begin{array}{c}0 \\
0 \\
-1\end{array}$ & $\begin{array}{l}-1 \\
-1\end{array}$ & \\
\hline 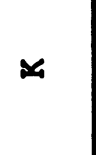 & $\begin{array}{c}m \\
0 \\
-1 \\
0 \\
0\end{array}$ & $\begin{array}{l}-1 \\
0 \\
0\end{array}$ & $\begin{array}{l}0 \\
\infty \\
0 \\
0 \\
0\end{array}$ & $\begin{array}{c}\infty \\
\infty \\
0 \\
0 \\
0 \\
0\end{array}$ & $\begin{array}{l}\infty \\
0 \\
0 \\
0 \\
0\end{array}$ & 1 & 1 & \\
\hline $\mathbb{\alpha}$ & $\begin{array}{l}0 \\
\dot{v}\end{array}$ & $\begin{array}{c}\vec{j} \\
\dot{\mathbf{N}} \\
\dot{N}\end{array}$ & $\begin{array}{c}\text { వू } \\
-1\end{array}$ & $\left|\begin{array}{c}m \\
o \\
-1\end{array}\right|$ & $\mathbf{N}$ & $\begin{array}{c}\infty \\
0 \\
-1\end{array}$ & $\begin{array}{l}0 \\
-i\end{array}$ & \\
\hline $\begin{array}{l}\text { 足卷 } \\
\text { 总 }\end{array}$ & : & $\begin{array}{l}\hat{m} \\
\dot{0}\end{array}$ & n & $\begin{array}{c}\text { n } \\
\text { N } \\
\text { - }\end{array}$ & $\begin{array}{c}N \\
\text { ก } \\
-1\end{array}$ & $\begin{array}{l}+ \\
0\end{array}$ & $\begin{array}{l}n \\
\alpha \\
0\end{array}$ & \\
\hline 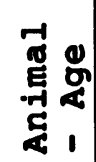 & $\begin{array}{c}m \\
1 \\
\frac{7}{\Sigma}\end{array}$ & \begin{tabular}{l}
+ \\
1 \\
\multirow{2}{2}{}
\end{tabular} & $\begin{array}{l}\infty \\
1 \\
m \\
z\end{array}$ & $\begin{array}{c}0 \\
1 \\
\Sigma \\
\Sigma\end{array} \mid$ & $\begin{array}{l}0 \\
1 \\
\sum \\
\Sigma\end{array}$ & $\begin{array}{c}\infty \\
1 \\
0 \\
\Sigma\end{array}$ & $\begin{array}{l}0 \\
7 \\
1 \\
\text { 돌 }\end{array}$ & $\Sigma$ \\
\hline
\end{tabular}


scan examination using ${ }^{18} \mathrm{~F}$-DOPA to measure DA function, and ${ }^{15} \mathrm{O}$-labeled water to measure blood flow. The preparation of the animal for the PET study and scanner characteristics have been described previously $/ 6 /$.

\section{Cerebral blood flow (CBF): ${ }^{15}$ O-labeled water studies}

CBF studies using 150-labeled water (10-20 $\mathrm{mCi}$ ) were performed before the $18 \mathrm{~F}$-DOPA studies at 4 transaxial $\mathrm{z}$ levels. Data acquisition began when radioactivity was registered in the brain. The rapid reconstruction of the data insured accurate verification of the position of the animal's head in the scanner. Blood sampling was usually not performed for the CBF studies. Because the CBF studies were performed immediately before the 3-4 h 18F-DOPA studies with arterial sampling, we wanted to reduce the amount of blood loss from each animal in a given study. Moreover, it was very unlikely that the absolute global or regional blood flows could be meaningfully compared across monkeys. Barbiturate administration and the depth of anesthesia are known to affect global and regional $\mathrm{CBF}$ results significantly and increase their variability. Furthermore, although the original barbiturate dose was the same in all animals, additional low doses were given as needed throughout the course of the study. Thus, there was likely to be significant variability in $\mathrm{pCO}_{2}$ as well as other parameters important for the valid calculation of absolute CBF across animals.

Since we compared primarily the CBF pattern in the ipsi- and contralateral basal ganglia of the hemi-parkinsonian animals, we only reconstructed the first $50-60 \mathrm{sec}$ of the data. During this period, regional CBF is linearly related to the amount of radioactivity in each region $/ 9,19 /$.

The data were stored in four sets of images corresponding to the injections at the four scanning levels. From the four sets of images, the slice where the basal ganglia was best represented was identified. In this slice, the striatum usually appears as a crescent that includes the head of the caudate nucleus and the dorsal part of the putamen (Fig. 1). Circular regions of interest (ROI) $\left(0.84 \mathrm{~cm}^{2}\right)$ were positioned around the left and right striata and occipital cortices on the same slice. Activity in the slice was determined by drawing a ROI around the brain using an edge finder.

Only normalized values were considered in the $\mathrm{CBF}$ analysis. In a preliminary report $/ 7 /$, the striatal data were normalized to the whole brain average. However, a more extensive analysis of the data showed that the amount of brain tissue included in the calculation of the whole brain average was variable depending on the number of slices containing the brain in the set of images from which the striatal slice was chosen. To homogenize the amount of brain tissue used in the normalization procedure, we decided to use only the activity in the slice containing the striatal ROIs. Regional data were normalized by dividing the regional values by the slice global value. Only normalized blood flow values were used for statistical purposes.

\section{F-DOPA studies}

18F-DOPA PET data acquisition and analysis were performed as previously described /4,6/. Kinetic and anatomical data were separated into two sets and analyzed separately.

An ROI was placed on the unaffected striatum and symmetrically relocated on the lesioned striatum. ROIs were also positioned on several posterior cortical areas and the temporalis muscles surrounding the monkey's head. For each ROI, time activity curves (TACs) were constructed from the kinetic data and the striatum/cortex ratio. Regional ${ }^{18} \mathrm{~F}$ accumulation was normalized to the amount of $\mathrm{mCi}$ injected per $\mathrm{kg}$ of body weight. The activity in the left and right posterior cortical areas and muscles was averaged. Repeated measures ANOVA was used to compare the ipsi- and contralateral TACs and the other groups.

For each animal, a representative mean striatum/cortex ratio was obtained by averaging the values obtained between 120 and $180 \mathrm{~min}$. The position of putamen and caudate nucleus ROIs was determined using previously described criteria $/ 6 /$. Ratios of $18 \mathrm{~F}$ accumulation values in putamen and caudate nucleus to a corresponding cortical area were interpolated at $120 \mathrm{~min}$.

Plasma and metabolite analyses were performed as described in detail elsewhere $/ 20 /$. Because of technical difficulties, the metabolic profile was 


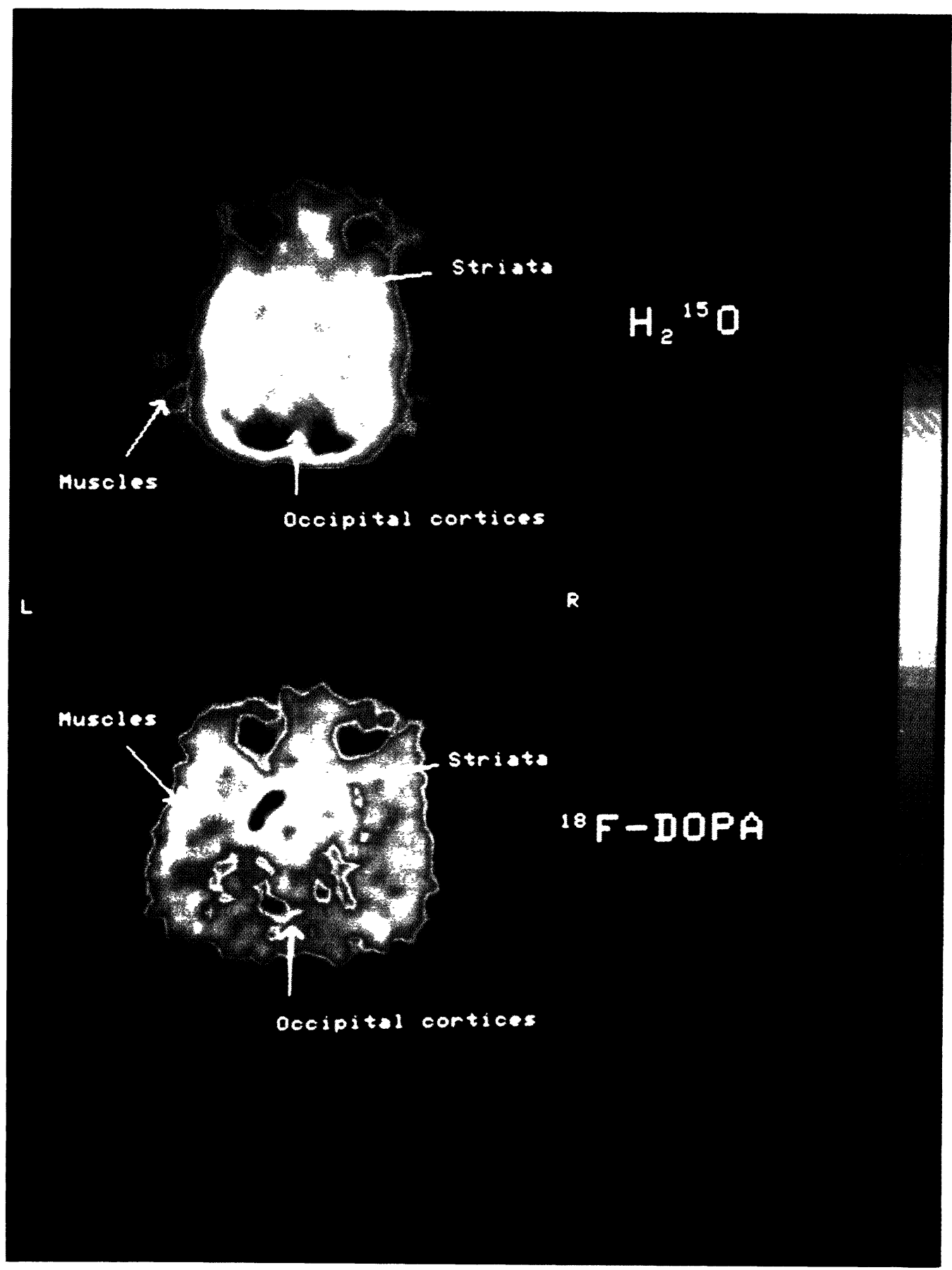

Fig. 1: Representative pictures of ${ }^{18} \mathrm{~F}$-DOPA (bottom) and ${ }^{15} \mathrm{O}$-labeled water (top) studies obtained in a unilaterally MPTPtreated rhesus monkey. Each image is color coded on its own scale. 
obtained in only 5 of the hemi-parkinsonian animals. A method derived from Patlak et al. $/ 25,26 /$ and Martin et al. $/ 18 /$ was used to perform a graphical analysis of the ${ }^{18} \mathrm{~F}$-DOPA data for these 5 animals. Because of the very small and, therefore, difficult to quantify accurately, amount $(<2 \%)$ of 18F-DOPA present in plasma after $90 \mathrm{~min}$, the graphical analysis was restricted to the first $90 \mathrm{~min}$ after isotope injection.

\section{Statistical analysis}

Monoamine metabolite concentrations in the cerebrospinal fluid (CSF) and PET data from 9 normal and 4 bilaterally MPTP-treated monkeys are reported in parallel to provide the reader with a basis for comparison with the data from the unilaterally lesioned animals (see Tables 2-4). All the values are reported as the average of the left plus right sides. These data were also used for statistical population comparisons. The bilaterally lesioned animals were characterized as neurologically normal, i.e., the home cage activity and posture were normal, they exhibited no hypokinesia or tremor and displayed normal feeding and vocalization behaviors. All 4 animals presented some cognitive impairments in the performance of tasks involving the frontal-striatal dopaminergic systems /4/. The normal and bilaterally lesioned animals were age, size and sex matched with the unilaterally MPTP-treated animals. The PET and CSF data were acquired during the same time frame, using the same procedures and analysis techniques as for the data in the unilaterally injected monkeys. ${ }^{18 F-D O P A}$ data, behavioral data and observations and MPTP administration schedule are described in detail elsewhere $/ 4,6 /$.

For the PET studies in the unilaterally treated monkeys, the ipsi- and contralateral sides were compared using Student's paired t-test. The comparisons between the three groups were performed by analysis of variance (ANOVA) with Bonferroni correction for multiple comparisons. The 18F-DOPA time activity curves were compared using repeated ANOVA. Left and right values were averaged to determine the correlations between $\mathrm{CBF}$ (normalized striatal $\mathrm{CBF}$ ) and ${ }^{18} \mathrm{~F}-\mathrm{DOPA}$ data (striatum/cortex ratios and uptake rate constants) and behavioral parameters. Correlations were analyzed using the least square analysis of the data.

For convenience, the ${ }^{18} \mathrm{~F}-\mathrm{DOPA}$ striatum/cortex ratio is referred to as RA in the text, and all regional $C B F$ values refer to normalized regional $\mathrm{CBF}$ values.

\section{RESULTS}

CSF catecholamine metabolites and behavioral data in the hemi-parkinsonian monkeys

At the time of PET scanning, monkeys M1 and M2 showed no signs of impairment. Monkey M8, the oldest animal, exhibited very moderate hypokinesia in the contralateral side and reduced activity in his home cage. When animals M3, M5 and M8 were at rest, their contralateral limbs remained in a flexed, characteristic posture. Monkeys M3, M4, M5, M6 and M7 preferentially used their ipsilateral arm to obtain a presented treat but readily used the contralateral arm as well when presented with multiple treats at the same time. The hypokinesia in the contralateral side was very mild. None of the MPTP-treated animals had resting tremor.

As expected, the unilaterally MPTP-treated monkeys spontaneously turned ipsilaterally to the side of the lesion. When challenged with apomorphine, they turned to the side contralateral to the lesion. No correlation was found between the turning behavior, either spontaneous or under apomorphine stimulation, and the CSF HVA, 5HIAA or MHPG, the striatum/cortex ratio, RA, the uptake rate constant, $\mathrm{K}$, or the $\mathrm{CBF}$ normalized values.

CSF data for each of the hemi-parkinsonian animals are summarized in Table 1. CSF HVA was significantly lower in the hemi-lesioned monkeys compared to normals $(p<0.0001)$, but higher, though non-significantly, than in the bilaterally MPTP-treated monkeys. CSF 5HIAA in the MPTPtreated animals was lower than in normals, although the difference was not statistically significant. CSF MHPG was similar in the three groups. When the three groups were combined, there was a significant correlation between the striatum/cortex ratio RA $(r=0.95, p<0.0001)$ and 


\section{TABLE 2}

Normalized regional blood flow values (mean $\pm \mathrm{SD}$ ) in normal controls, neurologically normal MPTP-treated monkeys and the left $(\mathrm{L})$ and right $(\mathrm{R})$ side of the unilaterally MPTP-treated animals. The number in parentheses indicates the number of subjects. The * indicates a significant difference $(p<0.05)$ compared with controls (ANOVA).

\begin{tabular}{||l|l|c|l|l||}
\hline & \multicolumn{1}{|c|}{$\begin{array}{c}\text { Normal } \\
(\mathrm{N}=8)\end{array}$} & $\begin{array}{c}\text { MPTP-treated } \\
(\mathrm{N}=4)\end{array}$ & $\begin{array}{c}\text { L Hemi MPTP } \\
(\mathrm{N}=8)\end{array}$ & $\begin{array}{c}\mathrm{R} \text { Hemi MPTP } \\
(\mathrm{N}=8)\end{array}$ \\
\hline Striatum & $1.070 \pm 0.083$ & $1.123 \pm 0.048$ & $1.148 \pm 0.054 *$ & $0.953 \pm 0.068 *$ \\
\hline Cortex & $1.261 \pm 0.077$ & $1.280 \pm 1.126$ & $1.328 \pm 0.097$ & $1.290 \pm 0.098$ \\
\hline
\end{tabular}

\section{TABLE 3}

Ratios striatum/cortex and rate constant for net uptake of ${ }^{18} \mathrm{~F}-\mathrm{DOPA}$ from blood to striatum in normal, asymptomatic MPTP-treated monkeys and the left and right side of the hemi-parkinsonian animals. The number in parentheses indicates the number of subjects. The * indicates a significant difference compared with controls and the non-lesioned side of the unilaterally MPTP-treated monkeys and the $\cdot$ a significant difference with the asymptomatic, bilaterally MPTP-treated animals.

\begin{tabular}{||l|l|l|l|l||}
\hline & \multicolumn{1}{|c|}{ Normal } & \multicolumn{1}{|c|}{ MPTP-treated } & \multicolumn{1}{c|}{ L Hemi MPTP } & \multicolumn{1}{c|}{ R Hemi MPTP } \\
\hline $\begin{array}{l}\text { Caudate/ } \\
\text { Cortex }\end{array}$ & $\begin{array}{l}2.634 \pm 0.16 \\
(\mathrm{~N}=9)\end{array}$ & $\begin{array}{l}1.84 \pm 0.091 * \\
(\mathrm{~N}=4)\end{array}$ & $\begin{array}{l}2.476 \pm 0.29 \\
(\mathrm{~N}=8)\end{array}$ & $\begin{array}{l}1.37 \pm 0.113 * \bullet \\
(\mathrm{N}=8)\end{array}$ \\
\hline $\begin{array}{l}\text { Putamen/- } \\
\text { Cortex }\end{array}$ & $\begin{array}{l}2.508 \pm 0.103 \\
(\mathrm{~N}=9)\end{array}$ & $\begin{array}{l}1.55 \pm 0.081 * \\
(\mathrm{~N}=4)\end{array}$ & $\begin{array}{l}2.455 \pm 0.338 \\
(\mathrm{~N}=8)\end{array}$ & $\begin{array}{l}1.351 \pm 0.14 * \bullet \\
(\mathrm{N}=8)\end{array}$ \\
\hline $\begin{array}{l}\text { Striatum/- } \\
\text { Cortex }\end{array}$ & $\begin{array}{l}2.752 \pm 0.29 \\
(\mathrm{~N}=9)\end{array}$ & $\begin{array}{l}1.735 \pm 0.099 * \\
(\mathrm{~N}=4)\end{array}$ & $\begin{array}{l}2.614 \pm 1.435 \\
(\mathrm{~N}=8)\end{array}$ & $\begin{array}{l}1.48 \pm 0.118 * \bullet \\
(\mathrm{N}=8)\end{array}$ \\
\hline $\begin{array}{l}\text { Uptake Rate } \\
\text { Constant }\end{array}$ & $\begin{array}{l}0.0146 \pm 0.0022 \\
(\mathrm{~N}=8)\end{array}$ & $\begin{array}{l}0.0051 \pm 0.0011^{*} \\
(\mathrm{~N}=3)\end{array}$ & $\begin{array}{l}0.0135 \pm 0.0012 \\
(\mathrm{~N}=5)\end{array}$ & $\begin{array}{l}0.0047 \pm 0.002 * 0 \\
(\mathrm{~N}=5)\end{array}$ \\
\hline
\end{tabular}

\section{TABLE 4}

CSF content in HVA, 5HIAA and HHPG (in pmol/ml) of normal, neurologically normal MPTP-treated and hemi MPTP-treated rhesus monkeys. The * indicates a significant difference from the normal control animals.

\begin{tabular}{|c|c|c|c|}
\hline & $\begin{array}{l}\text { Normal } \\
(N=9)\end{array}$ & $\begin{array}{l}\text { MPTP-treated } \\
(\mathrm{N}=4)\end{array}$ & $\begin{array}{l}\text { Hemi MPTP } \\
(\mathrm{N}=8)\end{array}$ \\
\hline HVA (pmol/ml) & $1332.8 \pm 222.4$ & $544.4 \pm 70.8^{\star}$ & $732.5 \pm 214.5 \star$ \\
\hline $5 \mathrm{HIA}(\mathrm{pmol} / \mathrm{ml})$ & $330.6 \pm 56.7$ & $285.2 \pm 29.8$ & $271.9 \pm 90.7$ \\
\hline MHPG (pmol/ml) & $85.7 \pm 12.6$ & $76.1 \pm 7.87$ & $91.8 \pm 27.8$ \\
\hline
\end{tabular}


the rate constant $\mathrm{K}(\mathrm{r}=0.91, \mathrm{p}<0.001)$ with the CSF HVA. There was a significant correlation between $\mathrm{RA}$, but not $\mathrm{K}$, and the CSF 5HIAA ( $\mathrm{r}=0.63$, $p=0.002$ ). There was no correlation between RA or $\mathrm{K}$ and the CSF MHPG.

There was a negative correlation $(r=-0.73$, $p=0.04$ ) between the age of the unilaterally lesioned animals and RA. There was no correlation with the dose of MPTP injected. However, because MPTP effects are known to be age dependent, we examined the strength of the correlation when age and dose of MPTP were combined. Several combinations of the two variables led to highly significant correlations with $R A$. The most significant were $R A$ vs $\ln ($ age + dose $)(r=-0.86$, $\mathrm{p}=0.006)$ and RA vs $\ln ($ age $*$ dose $)(r=-0.78$, $\mathrm{p}=0.021$ ).

\section{O-labeled water studies}

Data obtained in the hemi-parkinsonian animals are summarized in Tables 1 and 2. There was a statistically significant difference $(p<0.0001)$ between the left and right normalized blood flow striatal values, while no significant difference was apparent between the occipital areas (Fig. 1). The striatal CBF of the MPTP-treated side in the hemiparkinsonian animals was significantly decreased $(p=0.0035)$ compared to the normal and neurologically normal MPTP-treated monkeys. Values from the "normal" non-treated side were significantly increased $(p=0.04)$ compared to controls. Occipital CBF was similar in the normal and all the MPTP-treated animals. There was no significant correlation between the CBF data and any of the behavioral parameters (age, dose of MPTP, age-dose combination, spontaneous or apomorphine-induced turning).

\section{F-DOPA studies}

Data are summarized in Table 1 . In the striatum of the MPTP injected side, no ${ }^{18 F}$ accumulation was visually detectable in the entire striatum of 7 of 8 animals. A meager $18 \mathrm{~F}$ striatal accumulation was detectable in one slice of the youngest animal (M1). Striatal ${ }^{18} \mathrm{~F}$ activity was apparent in 4 to 5 slices of the anatomical set in the normal side of 7 of the 8 hemi-parkinsonian monkeys (Fig. 1). In the oldest animal (M8), $18 \mathrm{~F}$ accumulation was apparent in only 3 slices. The contrast between specific and non-specific accumulation was also poorer in these slices than in comparable slices obtained from the younger animals. The loss of $18 \mathrm{~F}$ accumulation from the non-injected side was also indicated by its lower RA value (Table 1 ).

There was a significantly lower ${ }^{18} \mathrm{~F}$ accumulation in the MPTP-lesioned striatum of the unilaterally treated animals compared to the nontreated side, normal controls and asymptomatic MPTP-treated monkeys (repeated measures ANOVA). There was no significant difference in striatal accumulation in the non-injected side compared with normal controls. The ${ }^{18} \mathrm{~F}$ accumulation in the posterior cortical areas and the surrounding muscles was similar in both sides and between the three groups.

As shown in Tables 1 and 3 and Fig. 2, the striatum, putamen and caudate/cortex ratios on the MPTP-injected side were significantly lower than those of the non-treated side $(p<0.01)$, and of normal control and clinically normal MPTP-treated animals $(\mathrm{p}<0.02)$. The striatum, putamen and caudate nucleus/cortex ratios in the non-injected side of the hemi-lesioned animals were not significantly different from normal controls (Table 3).

The mean rate constant, $\mathrm{K}$, for uptake of $18 \mathrm{~F}$ DOPA from blood into striatum was significantly lower in the lesioned side of the unilaterally MPTP-treated animals compared with the noninjected side $(p<0.0001)$ and normal control rhesus $(\mathrm{p}<0.0001)$ (Table 3 and Fig. 3). $\mathrm{K}$ was similar in normal monkeys and the intact side of the hemiparkinsonian animals.

There was no significant correlation between the CBF data and RA and $\mathrm{K}$ in all groups.

\section{DISCUSSION}

\section{F-DOPA PET data}

The 18F-DOPA studies revealed a large asymmetry in the striatum/cortex ratios and uptake rate constant between the MPTP-injected and noninjected sides of the hemi-parkinsonian animals. Our study, performed $12-25$ months after the last 


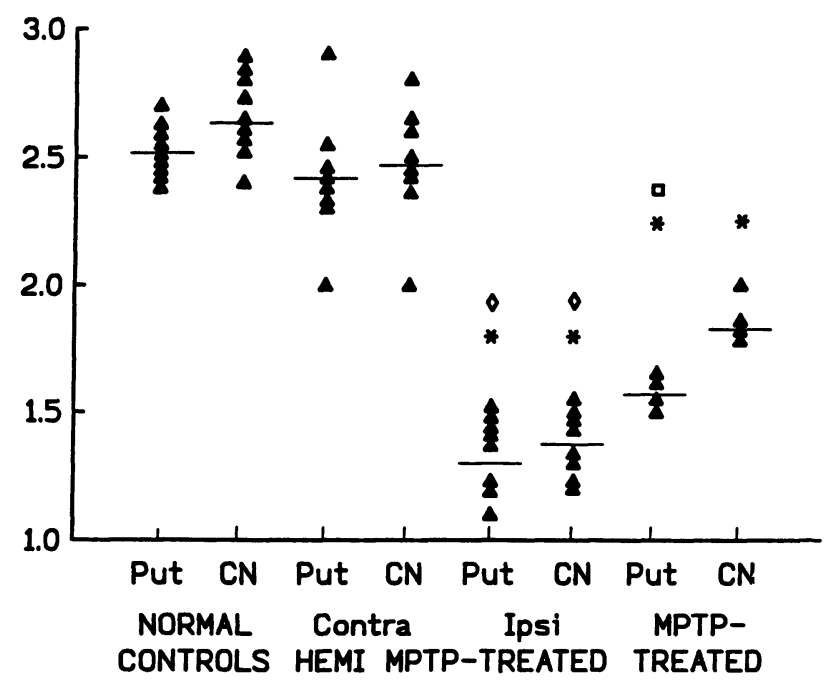

Fig. 2: The ratios putamen/cortex (Put) and caudate nucleus/cortex $(\mathrm{CN})$ at $120 \mathrm{~min}$ after $18 \mathrm{~F}$-DOPA injection. The filled triangles represent the values for each animal. The bars indicate the mean for each group. The ${ }^{*}$ indicates a significant difference between normal animals and the non-injected side of the hemi-lesioned monkeys and the bilaterally and unilaterally MPTP-lesioned animals $(p<0.01)$. The $\checkmark$ indicates a significant difference with the bilaterally MPTP-treated animals. The $\square$ indicates a significant difference between the caudate and putamen of the asymptomatic animals.

dose of MPTP, shows that the effects reported in acute and sub-chronic studies $/ 12,21 /$ are likely to remain even after the prolonged recovery period that has been found by others $/ 13 /$.

The striatum, caudate and putamen/cortex ratios of the MPTP-injected striatum are significantly lower than those of the normal controls and bilaterally MPTP-treated animals. In the bilaterally MPTP-treated monkeys, the caudate nucleus appeared less affected than the putamen (Fig. 2) $\mid 6 /$, but the caudate and putamen were equally affected in the hemi-parkinsonian preparation (Table 3). The putamen receives projections from the more ventral and posterior DA nigral neurons, which are also the most sensitive to MPTP neurotoxicity $/ 11,29 /$. The more resistant caudateprojecting neurons are increasingly affected with exposure to MPTP. When the drug is infused directly into the brain through the internal carotid artery, the dose of MPTP in contact with DA terminals is large and projections to both caudate

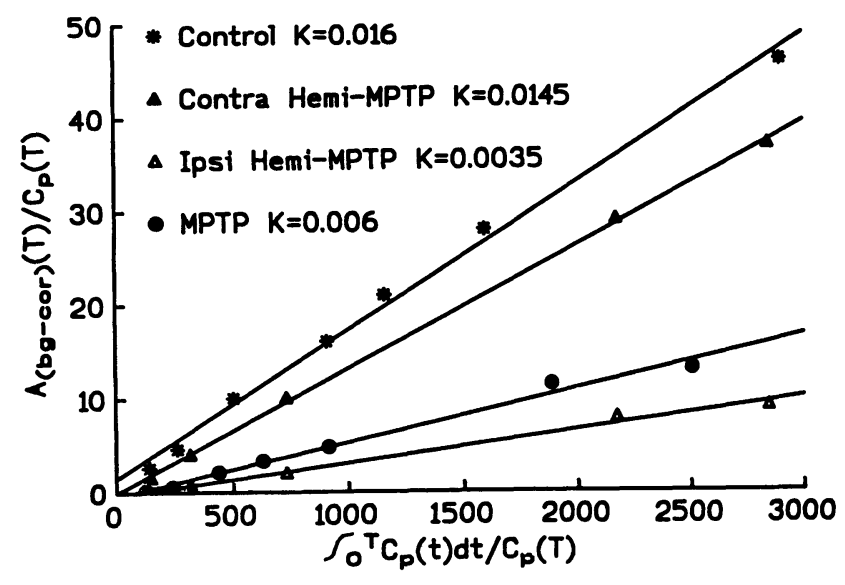

Fig. 3: Plots of the Patlak equation showing the relationship between specific striatal radioactivity (striatal activity minus reference area activity) and integrated plasma ${ }^{18} \mathrm{~F}$-DOPA activity during steady-state (30-90 min post injection). As proposed by Martin et al. $/ 18 /$, the slope of the regression line equals the rate constant for net uptake of $18 \mathrm{~F}$-DOPA from blood to striatum, $\mathrm{K}$ $(\mathrm{ml} / \mathrm{min} / \mathrm{ml})$. Data are shown in three animals representative of the three groups. For the normal $\left({ }^{*}\right)$ and bilaterally MPTP-treated monkeys (O), left and right data were averaged. Both lesioned $(\Delta)$ and non-injected $(\boldsymbol{\Lambda})$ sides of the unilaterally lesioned animal are shown.

nucleus and putamen are equally affected as evidenced by the equally low caudate and putamen/cortex ratios in the unilateral preparation.

The 18F-DOPA scans evaluated in this report did not reveal a significant lesion of the contralateral DA system (Table 1) in the animals as a group. However, if monkeys M1 and M2, i.e., the two animals devoid of manifest clinical symptoms, except for spontaneous ipsilateral turning, were excluded from the group, the striatum/cortex ratio in the non MPTP-injected side $(2.4 \pm 0.17)$ would be significantly lower than in normal controls $(2.75$ $\pm 0.29)(p=0.02)$. Furthermore, we have recently found evidence that this apparent normality may result from the relative insensitivity of the standard 18F-DOPA scanning technique used (i.e. low signal to noise ratio). Using a different, more sensitive scanning technique, these same animals were found to have reduced contralateral RA $/ 5 /$. We believe these more recent results reflect the likelihood that MPTP is not completely trapped in the striatum 
during its first pass, that MPTP is not totally metabolized by the liver before some of it is recirculated, and that some cross perfusion between the left and right arterial carotid system may occur.

\section{F-DOPA and biological parameters}

CSF HVA, and to a lesser extent CSF 5HIAA, and 18 F-DOPA PET data were strongly correlated. CSF HVA has been shown roughly to reflect the state of the DA system and DA activity in multiple clinical studies. The slightly lower levels of 5HIAA in both groups of MPTP-treated animals suggests that, at the dose used, MPTP may have induced some subtle damage to the serotonin pathways. No damage to the NE pathways is apparent from the CSF levels of MHPG. It is noteworthy that in many CSF studies in humans, changes in HVA and 5HIAA are closely paralleled while MHPG is not $/ 16 /$.

Neither spontaneous nor apomorphine-induced turning behaviors correlate with the 18F-DOPA PET data, dose of MPTP administered, the animal's age, or the CSF HVA content. ${ }^{18 F-D O P A}$ is considered a good marker of dopaminergic function, as is turning behavior in rodent students. The lack of correlations between these two parameters in our animals was surprising. It is likely that multiple factors may account for the discrepancy between the well established rodent model and the non-human primate model. For instance, MPTP's effects are not limited to the substantia nigra and DA systems $/ 22 /$. The control of turning behavior in the monkey may also differ from the rodent.

\section{Cerebral blood flow studies}

The CBF in the lesioned striatum of the unilaterally treated animals was significantly lower than that in the non-injected side and the normal controls. However, this decrease is unlikely to be responsible for the concomitant decrease in $18 \mathrm{~F}$ DOPA striatal accumulation. For instance, the bilaterally, neurologically normal MPTP-treated animals who had no significant changes in striatal CBF had a markedly decreased 18F-DOPA. Similarly, the striatum contralateral to the MPTP infusion presents an increase in blood flow with a normal accumulation of ${ }^{18} \mathrm{~F}$. Furthermore, there was no correlation between CBF and ${ }^{18} \mathrm{~F}-\mathrm{DOPA}$ data in the three groups.

The CBF data in monkeys may help clarify some of the CBF data reported in early and late stages of IPD. Compared to normal striatal CBF, the lesioned and unlesioned striata have, respectively, significantly lower and higher $\mathrm{CBF}$. In human subjects, there is little agreement in the literature on CBF in IDP. Some authors have found increased striatal CBF in some patients $/ 27 /$, others found it decreased $/ 30 /$ and some found it unchanged $/ 24 /$. Most of these differences could be due to the clinical stage of the patients at the time of the study. In humans, hemi-parkinsonism appears to represent a very early stage of the disease (Hoehn and Yahr I-II) with predominantly unilateral symptoms. Usually, 18F-DOPA PET scans reveal that substantial amounts of $18 \mathrm{~F}$-DOPA uptake in the striatum (especially in the caudate nucleus) contralateral to the affected limbs still remains $/ 10,23 /$. Classically, bilateral parkinsonian patients are in later stages of the disease (Hoehn and Yahr II-V) with pronounced impairment and little or no ${ }^{18} \mathrm{~F}-\mathrm{DOPA}$ striatal accumulation, especially in the putamen.

In the case of our MPTP-treated animals, the bilateral, clinically normal MPTP-treated monkeys and, perhaps, the non-injected side of the hemiparkinsonian animals may be considered very early or sub-clinical cases of DA degeneration. In contrast, the MPTP-injected side of the mild hemiparkinsonian animals, with little or no striatal ${ }^{18} \mathrm{~F}$ DOPA uptake left, may represent an example of more advanced DA degeneration as seen in more advanced stages of IPD. In this respect, our CBF data are in good concordance with the patient data. Roughly, CBF appears increased in the basal ganglia in the very early stages (Hoehn and Yahr III) of hemi-parkinsonism in patients $/ 27,30 /$. In our animals, in the slightly affected striatum, i.e. in the asymptomatic bilateral rhesus or the striatum contralateral to the MPTP infusion, CBF appears higher than in normal controls, even though not always significantly. This increase in striatal $\mathrm{CBF}$ may represent a compensatory phenomenon, an adaptation to limited nigro-striatal degeneration. After a unilateral lesion, reorganization processes 
take place in both nigro-striatal systems and may be mediated by increased synaptic DA activity in the remaining neurons or by adaptative phenomena in other neurotransmitter systems. It was impossible to assess whether this apparent basal ganglia increased CBF was the result of increased $\mathrm{CBF}$ in the pallidum as suggested by Perlmutter and Raichle /27/.

The significant decrease in striatal CBF observed in the basal ganglia contralateral to the mildly impaired limbs of the hemi-parkinsonian animals parallels earlier reports showing reduced striatal CBF in parkinsonian patients in advanced stages of the disease 130/. Wolfson et al. /30/ suggested that this decrease in CBF could be mediated by loss of DA innervation within the blood vessels. There are few data on the effects of MPTP on the blood-brain barrier and the DA innervation of the arterial wall. However, it is likely that the high doses of MPTP circulating within the anterior cerebral artery affect DA innervation in the vessels. Studies in cats and humans showed that DA antagonists block vasodilatation /8/. Drastic loss of DA innervation in the arteries may lead to decreased CBF through increased vasoconstriction.

Alternatively, this striatal decrease may be due to a generalized loss of function in the striatal areas, involving non-DA neurons as well as DA neurons, since the latter only represent $10 \%$ or less of the population. We did not examine CBF in the frontal cortical areas in our animals. The difficulty in identifying this area accurately in our scanning plane and the extensive partial voluming artifacts we would have encountered, would have made the frontal cortex determination subject to considerable error. However, our behavioral studies suggest that some frontal cortical functions in the MPTP-treated animals are impaired. The combination of the loss of DA innervation in the arterial wall and the striatum and abnormal cortico-striatal and nigrostriatal-induced functions may play a role in the decrease in striatal CBF observed.

In conclusion, the model of dopamine deficiency induced by unilateral infusion of MPTP presents some, but not all, of the features of IDP. It may be possible to mimic various stages of impairment by careful gradation of the dose of
MPTP used in each single animal. This particular model has already proven very helpful in the development of transplantation techniques. The use of ${ }^{18 F-D O P A}$ and even CBF studies may be good markers for the magnitude of the lesion and of the success of the graft. However, turning behavior and neurological observations of the animals may not be the most effective methods to evaluate changes in DA function, since, in the MPTP model, they appear to have little correlation with the actual amount of striatal DA after complete behavioral recovery of the acute and sub-chronic effects of MPTP.

Partial, preliminary data were reported in the proceedings of the Symposium on Alzheimer's and Parkinson's Disease: Basic and Therapeutic Strategies, Kyoto, Japan, $1989 / 7 /$.

\section{REFERENCES}

1. Bankiewicz KS, Oldfield EH, Chiueh CC, Doppman JL, Jacobowitz DM, Kopin IJ. Hemiparkinsonism in monkeys after unilateral internal carotid artery infusion of 1-methyl-4-phenyl-1,2,3,6-tetrahydropyridine (MPTP). Life Sci 1989; 39: 7-16.

2. Burns RS, Chiueh CC, Markey SP, Ebert MH, Jacobowitz DM, Kopin IJ. A primate model of parkinsonism: selective destruction of dopaminergic neurons in the pars compacta of the substantia nigra by N-methyl-1,2,3,6-tetrahydropyridine. Prog Brain Res 1983; 80: 4546-4550.

3. Davis GC, Williams AC, Markey SP, Ebert MH, Caine ED, Reichert CM, Kopin IJ. Chronic parkinsonism secondary to intravenous injection of meperidine analogues. Psychiatry Res 1979; 1: 249-254.

4. Doudet DJ, Aigner TG, McLellan CA, Cohen RM. ${ }^{18} \mathrm{~F}$ DOPA PET scans: interpretation and biological correlates in non-human primates. Psychiatry Res 1992; 45: 153-168.

5. Doudet DJ, McLellan CA, Aigner TG, Wyatt RJ, Adams HR, Miyake H, Finn RT, Cohen RM. Postinjection L-phenylalanine increases basal ganglia contrast in PET scans of 6-18F-DOPA. J Nucl Med 1991; 32: 1408-1413.

6. Doudet DJ, Miyake H, Finn RT, McLellan CA, Aigner TG, Wan RQ, Adams HR, Cohen RM. 6-18F-L-DOPA imaging of the dopamine neostriatal system in normal and neurologically-normal MPTP-treated rhesus monkeys. Exp Brain Res 1989; 78: 69-80.

7. Doudet DJ, Miyake H, Suddath R, Aigner TG, Wyatt RJ, Cohen RM. Striatal presynaptic dopaminergic function and cerebral blood flow in the MPTP primate 
model of Parkinson's disease by PET. In: Nagatsu T, Fisher A, Toshida M, eds, Alzeimer's and Parkinson's Diseases II: Basic and Therapeutic strategies. New York: Plenum Press 1990; 87-90.

8. Edvinsson L, Hardebo JE, McCulloch J, Owman $\mathrm{CH}$. Effects of dopaminergic agonists and antagonists on isolated cerebral blood vessels. Acta Physiol Scand 1978; 104: 349-359.

9. Fox PT, Mintun MA, Raichle ME, Herscovitch. A noninvasive approach to quantitative functional brain mapping with $\mathrm{H} 2150$ and positron emission tomography. J Cereb Blood Flow Metab 1984; 4: 329 335.

10. Garnett ES, Nahmias C, Firnau G. Central dopaminergic pathways in hemiparkinsonism examined by positron emission tomography. Can J Neurol Sci 1984; 11: 174-179.

11. German DC, Dubach M, Askari S, Speciale SG, Bowden DM. 1-methyl-4-phenyl-1,2,3,6-tetrahydropyridine-induced parkinsonian syndrome in Macaca fascicularis: which midbrain dopaminergic neurons are lost? Neuroscience 1988; 24: 161-174.

12. Guttman M, Yong VW, Kin SU, Calne DB, Martin WRW, Adam MF, Ruth TJ. Asymptomatic striatal dopamine depletion: PET scans in unilateral MPTP monkeys. Synapse 1988; 2: 469-473.

13. Kurlan R, Kin MH, Gash DM. The time course and magnitude of spontaneous recovery of parkinsonism produced by intracarotid administration of 1-methyl-4phenyl-1,2,3,6-tetrahydropyridine to monkeys. Ann Neurol 1991; 29: 677-679.

14. Langston JW, Ballard PA, Tetrud JW, Irwin I. Chronic parkinsonism in humans due to meperidine-analog synthesis. Science 1983; 219: 979-980.

15. Langston JW, Irwin I. MPTP: Current concepts and controversies. Clin Neuropharmacol 1986; 9: 485-507.

16. Linnoila $M$, Niwan PT, Scheinin M, Winters RN, Chang WH, Bartko J, VanKammen DP. Reliability of norepinephrine and major monoamine metabolite measurement in CSF of schizophrenic patients. Arch Gen Psych 1983; 40: 1290-1294.

17. Marshall JF, Ungerstedt U. Supersensitivity to apomorphine following destruction of the ascending dopamine neurons: quantification using the rotational model. Eur J Pharmacol 1977; 41: 361-367.

18. Martin WRW, Palmer MR, Patlak CS, Calne DB. Nigrostriatal function in humans studied with positron emission tomography. An Neurol 1989; 26: 535-542.

19. Mazziotta JC, Huang SC, Phelps ME, Carson RE, MacDonald NS, Mahoney K. A noninvasive positron computed tomography technique using oxygen-15- labeled water for the evaluation of neurobehavioral task batteries. J Cereb Blood Flow Metab 1985; 5: 70-78.

20. McLellan CA, Doudet DJ, Brucke T, Aigner TG, Cohen RM. New rapid analysis method demonstrates differences in 6-[ ${ }^{18}$ F $]$ fluoro-L-dopa plasma input curves with and without carbidopa and in hemi-MPTP lesioned monkeys. Appl Radiat Isot 1991; 42: 847-854.

21. Melega WP, Hoffman JM, Schneider JS, Phelps ME, Barrio JR. 6-18 F Fluoro-L-Dopa metabolism in MPTPtreated monkeys: assessment of tracer methodologies for positron emmission tomography. Brain Res 1991; 543: 271-276.

22. Mitchel IJ, Cross AJ, Sambrook MA, Crossman AR. Sites of the neurotoxic action of 1-methyl-4-phenyl1,2,3,6-tetrahydropyridine in the macaque monkey include the ventral tegmental area and the locus coeruleus. Neurosci Lett 1985; 61: 195-200.

23. Nahmias C, Garnett ES, Firnau G, Lang AE. Striatal dopamine distribution in parkinsonian patients during life. J Neurol Sci 1985; 69: 223-230.

24. Otsuka M, Ichiya Y, Hosokawa S, Kuwabara Y, Tahara T, Fukumura T, Kato M, Masuda K, Goto I. striatal blood flow, glucose metabolism and ${ }^{18} \mathrm{~F}$-Dopa uptake: difference in Parkinson's disease and atypical Parkinsonism. J Neurol Neurosurg Psychiatry 1991; 54: 898-904.

25. Patlak CS, Blasberg RG. Graphical evaluation of blood-to-brain transfer constants from multiple-time uptake data. Generalizations. J Cereb Blood Flow Metab 1985; 5: 584-590.

26. Patlak CS, Blasberg RG, Fenstermacher ID. Graphical evaluation of blood-to-brain transfer constants from multiple-time uptake data. J Cereb Blood Flow Metab 1983; 3: 1-7.

27. Perlmutter JS, Raiche ME. Regional blood flow in hemi-parkinsonism. Neurology 1985; 35: 1127-1134.

28. Scheinin $M$, Chang WH, Kirk KL, Linnoila $M$. Simultaneous determination of 3-methoxy-4hydroxyphenylglycol, 5-hydroxyindolacetic acid and homavanillic acid in cerebrospinal fluid with highperformance liquid chromatography using electrochemical detection. Anal Biochem 1983; 131: 246-253.

29. Schneider JS, Yuwilder A, Markham CH. Selective loss of subpopulations of ventral mesencephalic dopaminergic neurons in the monkey following exposure to MPTP. Brain Res 1987; 411: 144-150.

30. Wolfson $\mathrm{LI}$, Leenders $\mathrm{KL}$, Brown $\mathrm{LL}$, Jones $\mathrm{T}$. Alterations of regional cerebral blood flow and oxygen metabolism in Parkinson's disease. Neurology 1985; 35: $1399-1405$. 

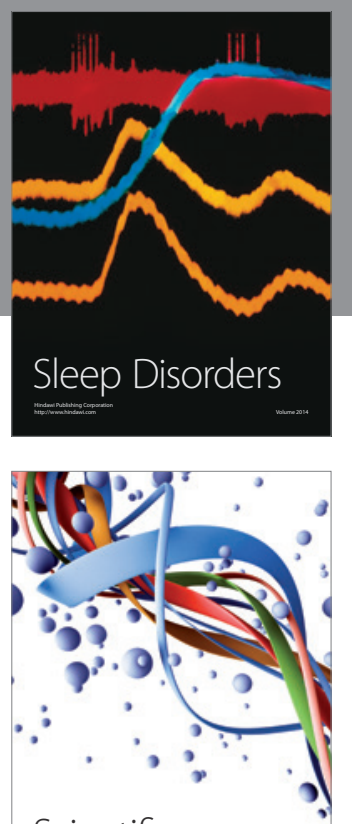

Scientifica
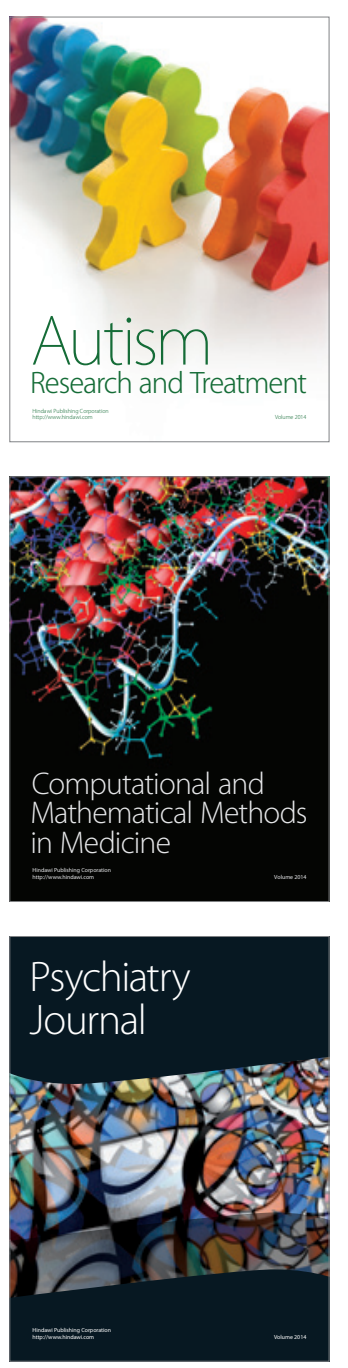
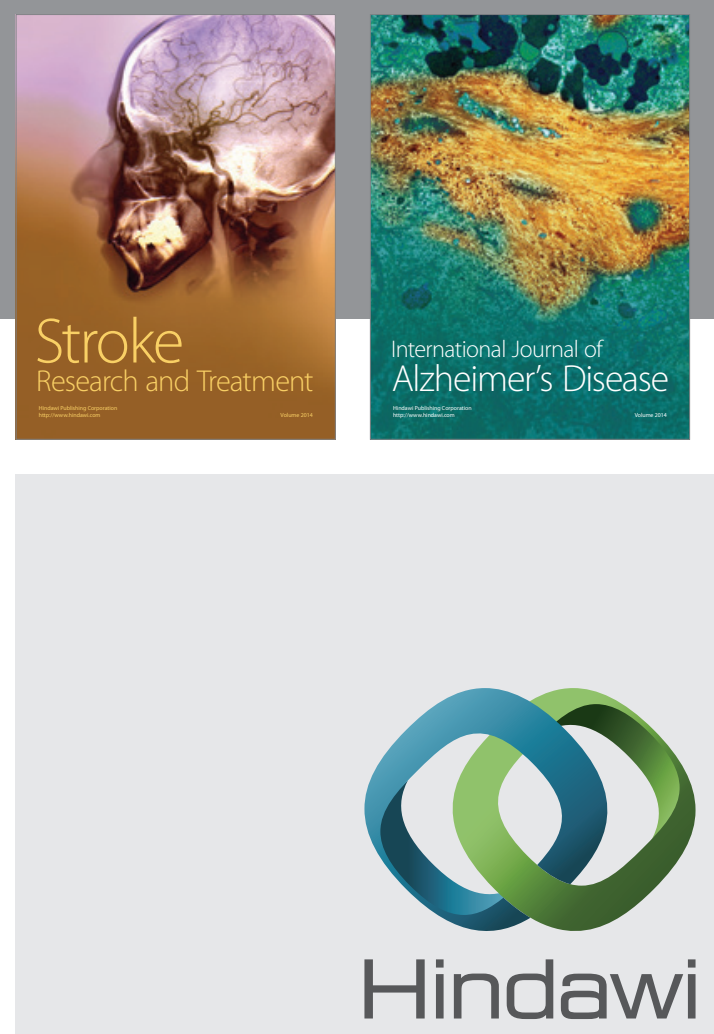

Submit your manuscripts at

http://www.hindawi.com
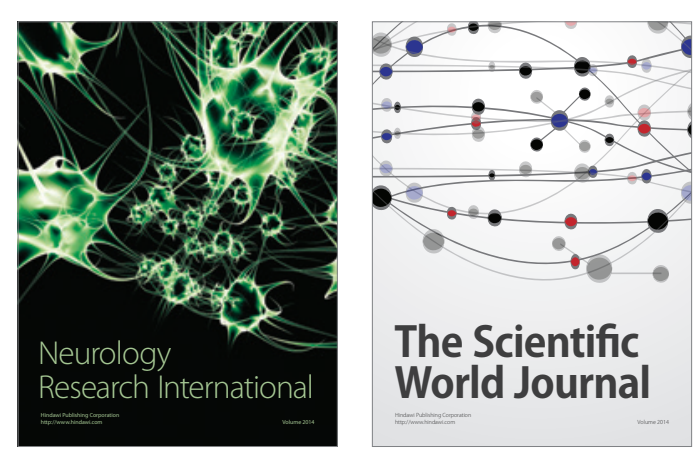

The Scientific World Journal

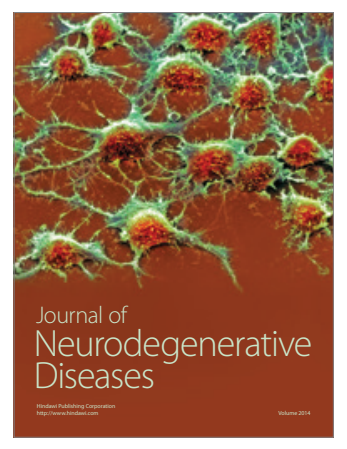

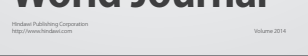

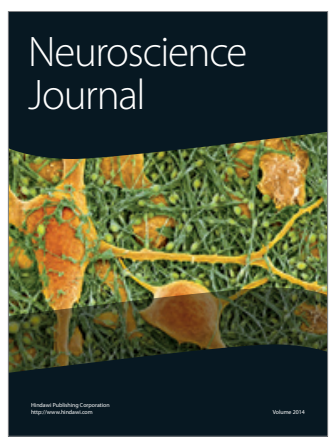

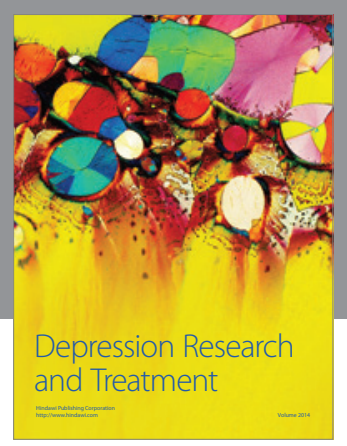
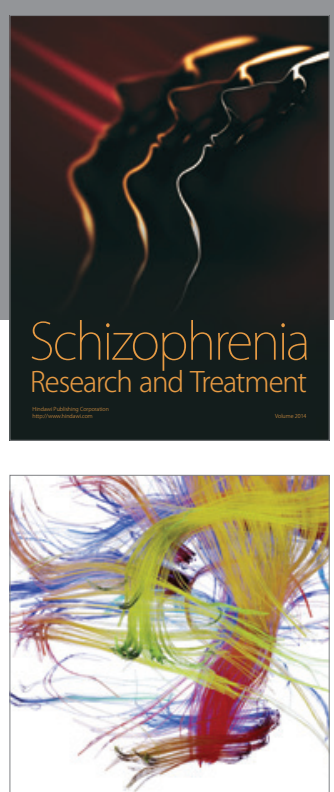

Brain Science

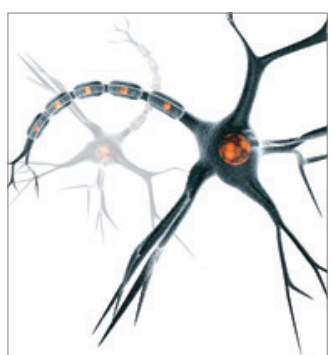

Neural Plasticity
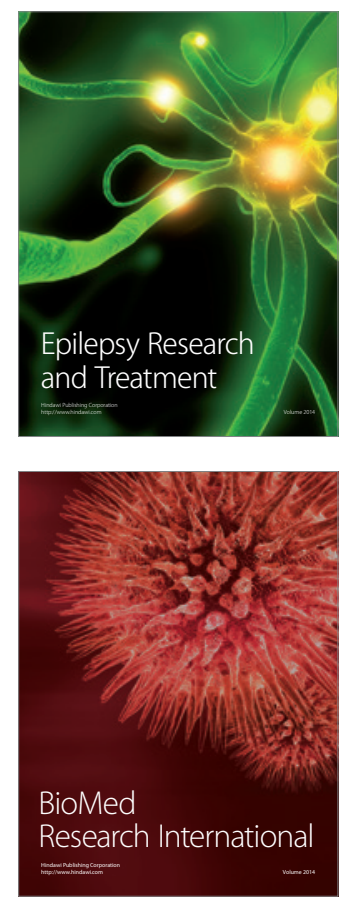

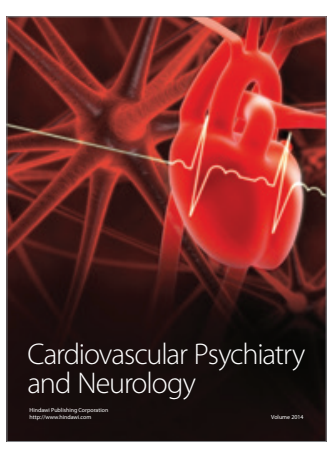

Parkinson's

Disease
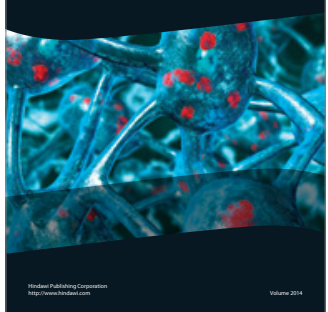